\title{
Pelatihan Budidaya Sayuran Secara Vertikultur di Pekarangan Guna Ketahanan Pangan Rumah Tangga
}

\author{
Endah Djuwendah*1, Tuti Karyani², Zumi Saidah ${ }^{3}$, O. Hasbiansyah ${ }^{4}$ \\ 123 Program Studi Agribisnis Fakultas Pertanian, Universitas Padjadjaran \\ ${ }_{4}^{4}$ Program Studi Manajemen Komunikasi, Universitas Islam Bandung \\ e-mail: endah.djuwendah@unpad.ac.id ${ }^{1}$, tuti.karyani@unpad.ac.id², zsaidah@gmail.com³ \\ hasbians@yahoo.com ${ }^{4}$
}

\begin{abstract}
One of the efforts to increase food sufficiency, resilience and self-sufficiency is the use of the yard. Cultivation of vegetables using verticulture techniques can be applied in the use of yards. The verticulture technique was chosen because it has advantages: it does not require large costs, is easy, can be a source of family food, the beauty of the home and the environment and produces oxygen. This training activity aims to introduce vegetable farming techniques with the verticulture system as an effort to strengthen household food security. Participants in the activity were members of the Kencana Lestari Women's Farmer Group, Rancaekek Kencana Village, Bandung Regency. The methods used in this activity are lectures, practice and mentoring. The methods used in this activity are lectures, practice and mentoring. This activity has provided benefits for activity participants. The result was that there was a significant change in cognitive terms, namely an increase in the level of participants' knowledge about vegetable cultivation techniques using the verticulture system. For the psychomotor aspect, there is an increase in the skills of participants to cultivate various types of vegetable plants using verticulture techniques.
\end{abstract}

Keywords: vegetable cultivation, verticulture, yards

\section{Abstrak}

Salah satu upaya meningkatkan kecukupan, ketahanan, dan kemandirian pangan adalah pemanfaatan lahan pekarangan. Budidaya sayuran dengan teknik vertikultur dapat diterapkan dalam pemanfaatan lahan pekarangan. Teknis vertikulture dipilih karena memiliki kelebihan: yaitu tidak membutuhkan biaya besar, cara yang mudah, dapat menjadi sumber pangan keluarga, keindahan rumah dan lingkungan serta penghasil oksigen. Kegiatan pengabdian kepada masyarakat ini bertujuan untuk mengenalkan teknik bertanam sayuran dengan sistem vertikultur sebagai upaya memperkuat ketahanan pangan rumah tangga. Peserta dari kegiatan ini adalah anggota Kelompok wanita tani Kencana Lestari di Kelurahan Rancaekek Kencana Kabupaten Bandung. Metode yang dilakukan dalam kegiatan ini adalah ceramah, praktek dan pendampingan. Kegiatan ini telah memberikan manfaat bagi peserta. Hasil yang dirasakan adalah terjadi perubahan yang cukup signifikan dari sisi kognitif, yaitu bertambahnya tingkat pengetahuan peserta tentang teknik budidaya tanaman sayuran dengan sistem vertikultur. Untuk aspek psikomotorik terdapat peningkatan keterampilan peserta untuk membudidayakan berbagai macam jenis tanaman sayuran dengan teknik vertikultur.

Kata kunci: budidaya sayuran, vertikulture, pekarangan

\section{PENDAHULUAN}

Ketahanan pangan merupakan isu global. Pentingnya pangan sebagai kebutuhan mendasar bagi setiap manusia menjadikan pemenuhan kebutuhan pangan merupakan prioritas utama dalam pembangunan. Ketahanan pangan mencakup faktor ketersediaan, distribusi dan konsumsi. Ketersediaan berarti tercukupinya pasokan pangan untuk memenuhi kebutuhan penduduk. Distribusi adalah mewujudkan penyaluran yang efektif dan efisien untuk menjamin masyarakat dapat memperoleh pangan dalam jumlah, kualitas dan dengan harga yang terjangkau. Konsumsi adalah pola pemanfaatan pangan agar memenuhi kaidah mutu, keragaman, kandungan gizi dan kehalalannya (Prabowo, 2010).

Terdapat tantangan dalam pemenuhan kebutuhan pangan diantaranya perubahan iklim, alih fungsi lahan, sawah, serangan hama dan penyakit tanaman yang menyebabkan terjadinya penurunan hasil panen. Oleh karena itu perlu upaya untuk mengoptimalkan pemanfaatan lahan 
guna meningkatkan kecukupan, ketahanan, dan kemandirian pangan masyarakat. Salah satu hal yang dapat dilakukan adalah pemanfaatan lahan pekarangan. Pekarangan dinilai memiliki fungsi dan manfaat yang penting bagi setiap rumah tangga, Apabila dikelola dengan baik pekarangan memiliki potensi untuk memberikan manfaat dalam menunjang kebutuhan gizi keluarga sekaligus keindahan (estetika) (Rauf, Rahmawaty, \& Budiati, 2013). Menurut Ahmad Sarwadi (2018), pemanfaatan lahan pekarangan, lahan sempit dan terbatas di permukiman perkotaan, diharapkan dapat menambah kesediaan pangan seperti dengan tanaman buah dan sayuran.

Pertanian di area perkotaan dapat dirancang dengan konsep pertanian vertikal atau taman vertikal (vertical garden) supaya pemanfaatan pekarangan meningkatkan keterjangkauannya masyarakat akan ketersediaan pangan keluarga.. Vertikultur merupakan teknik bercocok tanam diruang/lahan sempit dengan memanfaatkan bidang vertikal sebagai tempat bercocok tanam yang dilakukan secara bertingkat. Menurut Nurul Hidayat dkk dkk (2018) Vertikultur adalah pola bercocok tanam yang menggunakan wadah tanam vertikal untuk mengatasi keterbatasan lahan. Tempat media vertikultur dapat menggunakan bambu, talang, rak kayu bertingkat dll. Media tanam digunakan bisa campuran tanah, kompos, dan sekam. Jenis tanaman yang ditanam dari tanaman sayursayuran dan sayuran buah serta tanaman hias.

Kendala yang dihadapi dalam pemanfaatan lahan untuk pertanian perkotaan (urban farming) adalah keterbatasan luas lahan sehingga berkebun jadi $\mathrm{k}$, urang leluasa. Namun dengan memanfaatkan ruang secara vertikal, berkebun menjadi lebih menyenangkan dengan kuantitas yang dapat ditingkatkan. Perumahan yang tidak mempunyai lahan pekarangan tetapi masih mempunyai ruang terbuka masih dapat dimanfaatkan sebagai penghasil tanaman misalnya di atas bangunan atau menepel di dinding bangunan.

Fenomena tersebut terjadi di Kelurahan Rancaekek Kencana Kabupaten bandung. Kelurahan Rancaekek kencana berada di dataran rendah dengan ketinggian 794 meter dari permukaan lautdan berdisi sejak Tahun 2012. Secara administrtif kelurahan ini membawahi 18 RW dan 133 RT dan 2 dusun, meliputi lahan seluas 109,42 hektare dengan jumlah penduduk sebanyak 28.088 orang (BPS, 2018). Hampir 80\% dari luasan tersebut digunakan sebagai pemukiman penduduk rumah tangga rata-rata hanya memiliki lahan pekarangan kurang dari 10 m2. Upaya menghidupkan kembali lahan pekarangan sebagai sumber gizi keluarga di Kelurahan Rancaekek kencana ditempuh melalui pemberdayaan masyarakat guna meningkatkan kemandirian dan kapasitas masyarakat untuk berperan aktif dalam mewujudkan ketersediaan, distribusi dan konsumsi pangan dari waktu kewaktu. Oleh karean itu perlu dilakukan pelatihan partisipatif budidaya tanaman sayuran dengan teknik vertikultur untuk meningkatkan ketahanan pangan keluarga sebagai salah satu upaya untuk memberdayakan masyarakat, baik komunitas maupun secara kelembagaan.

Sasaran dari kegiatan ini adalah ibu-ibu rumah tangga yang tergabung dalam kelompok Wanita tani (KWT) Kencana Lestari berjumlah 30 orang. Tujuan kegiatan pengabdian kepada masyarakat ini adalah meningkatkan pengetahuan dan keterampilan ibu rumah tangga anggota KWT dalam membudidayakan tanaman sayuran dengan teknik vertikulture, sehingga mereka dapat mempraktekannya di rumah masing-masing dan dapat menularkan pengetahuan serta keterampilan yang dimiliki kepada warga di sekitar tempat tinggal mereka.

\section{METODE}

Metode yang digunakan dalam kegiatan pengabdian ini adalah pemberdayaan partisipatif berupa penyuluhan, pelatihan dan pendampingan dengan melibatkan peran serta mitra yaitu kelompok wanita tani kencana secara aktif mulai dari perencanaan, pelaksanasan, monitoring dan evaluasi. Pendampingan dan fasilitasi dilakukan dalam mengontrol kegiatan selanjutnya agar kegiatan ini dapat terus diaplikasikan dan dikembangkan oleh masyarakat. 
Materi pelatihan yang diberikan adalah teknis budiadaya sayuran secara vertikulture di lahan pekarangan dengan memanfaatkan barang bekas sebagai wadah media tanam dan analisis biaya dan penerimaan usahatani sayuran secara vertikulture di lahan pekarangan. .

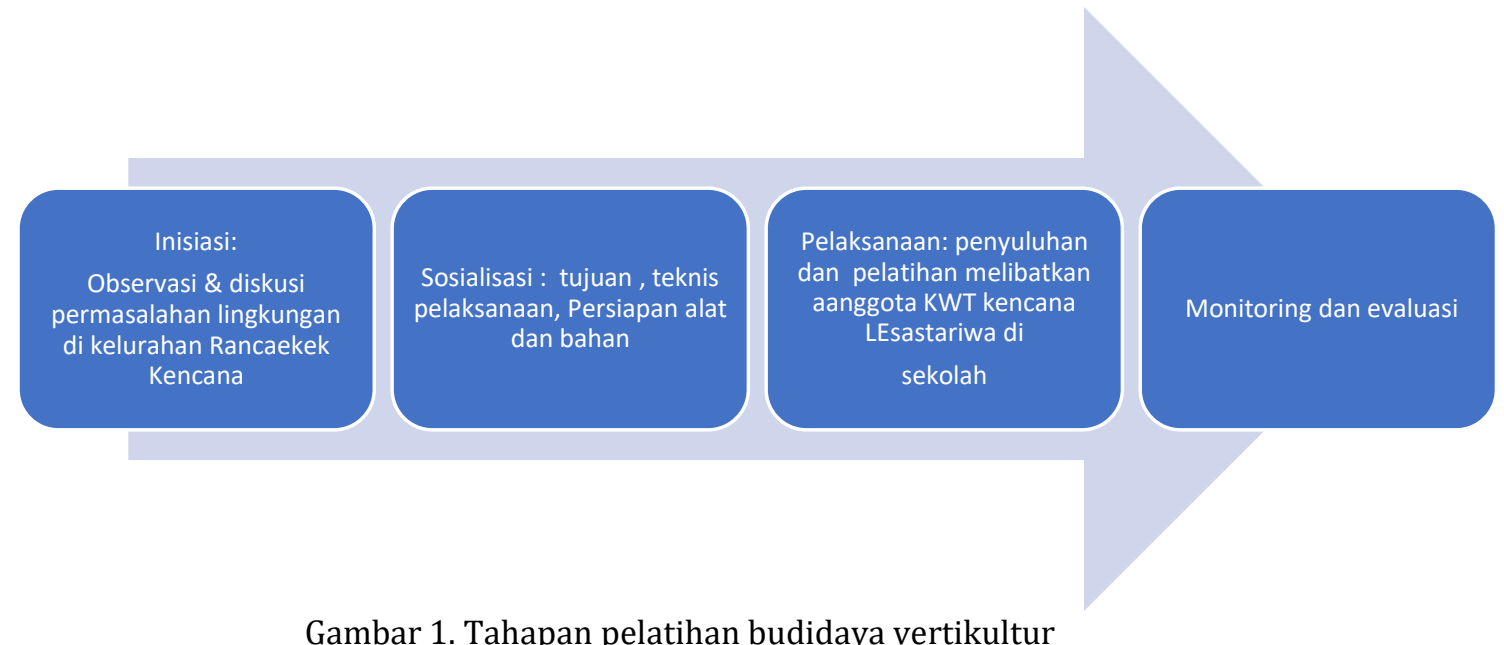

Gambar 1. Tahapan pelatihan budidaya vertikultur

Pada Gambar 1 dapat diketahui terdapat 4 tahapan pelaksanaan PKM Pelatihan budidaya sayuran secara vertikultue mulai dari inisasi, sosialisasi, pelaksanaan, monitoring dan evaluasi.

\section{HASIL DAN PEMBAHASAN}

Kelompok Wanita Tani (KWT) Kencana Lestari merupakan kelembagaan yang memegang peranan penting untuk pelibatan kaum perempuan secara langsung dalam usaha peningkatan hasil pertanian, motivator dalam adopsi dan pengenalan teknologi tani, baik dalam bidang bertanam sayur mayur dan membuat kemasan panganan yang menarik untuk di pasarkan.KWT ini berdiri berdasarkan SK Kelurahan Rancaekek Kencana No 09/Kp06/2016 ( KWT, 2020). Pelaksanaan PKM berlangsung pada bulan Juni 2020. Acara berlasung di di Ruang serba guna Kelurahan Rancaekek Kencana dan kebun KWT yang beralamat di Jalan Teratai Raya Blok 12 Rancaekek Kencana Bandung.

\section{Penyuluhan Teknis Budidaya Sayuran secara Vertikulture}

Pemanfaatan teknik vertikultur memungkinkan berkebun dengan memanfaatkan pekarangan terbatas secara efisien. Teknis budidaya vertikultur, secara estetis dapat penutup pemandangan yang tidak menyenangkan atau sebagai latar belakang yang menyuguhkan pemandangan yang indah dengan berbagai warna dan bentuk daun tanaman. Teknis budidaya secara vertikultur sangat sederhana, mudah diikuti dan dipraktekan. Bahan-bahan yang digunakan juga mudah ditemukan seperti polibag, pot plastik, bahkan dapat memanfaatkan barang bekas seperti paralon, botol kemasan air minum, drum, jerigen, dl. Oleh karena itu dapat diterapkan oleh ibu-ibu rumah tangga. Jenis-jenis tanaman yang dibudidayakan adalah sayuran daun yang memiliki sistem perakaran yang tidak terlalu luas, berumur pendek dan bernilai ekonomi tinggi, seperti bayam, kangkung, seledri, caisin, packcoy, baby kalian, dan selada.

Pelatihan dimulai dengan cara ceramah dan visualisasinya menggunakan power point. untuk menjelaskan arti dan manfaat vertikultur, jenis tanaman yang cocok untuk dibudidayakan secara vertikulture dan teknik bercocok tanam sayuran di lahan pekarangan yang sempit mulai dari persiapan media tanam, persemaian, penanaman, pemeliharaan dan pasca panen. Sarana yang digunakan dalam urban farming "vertikultur" dapat beragam, antara lain: model, ukuran dan 
jenis bahannya. Namun yang mendapat perhatian (penting) bahwa sarana tersebut harus mudah dibuat dan dipelihara oleh penggunanya.

Selanjutnya dilakukan praktek demo pembuatan wadah tanaman dan teknik budidaya sayuran secara vertikulture. Kegitatan dimulai dari penyediaan media tanam dan bibit tanaman. Peserta diberi pejelasan mengenai ciri dan komposisi media tanam yang baik menggunakan tanah gembur, pupuk kompos dan arang sekam dengan rasio 1: 3. Ciri benih dan bibit yang baik serta teknis penyemaian tanaman. Selanjutnya membuat wadah untuk media tanam berupa pot vertikal dari bahan bekas kemasan air mineral dan fanta. Langkah pembuaan pot adalah sebagai berikut : (a ) Pot vertikal : siapkan botol bekas air mineral ukuran 1,5 lietr, tali tambang paku dan cuteter untuk melubangai botol dan buat lubang besar menggunakan cutter atau gunting dengan lebar $3 \mathrm{~cm}$ panjang disesuaikan selera dan buat lubang kecil $0,2 \mathrm{~cm}$ di bagian bawah botol air mineral untuk memasukan tali pengantung, (b) pot biasa : botol bekas kemasan air mineral dipotong menjadi 2 bagian, lubangi tutup botol menggunakan paku yang telah dipanaskan, gabungkan kedua bagian botol dengan membalikan bagian moncong menghadap ke bawah, pasang sumbu kompor atau kain planel yang sudah sigunting memaanjang yang befungsi sebagai sumbu untuk mengalrkan air dan zat nutrisi .
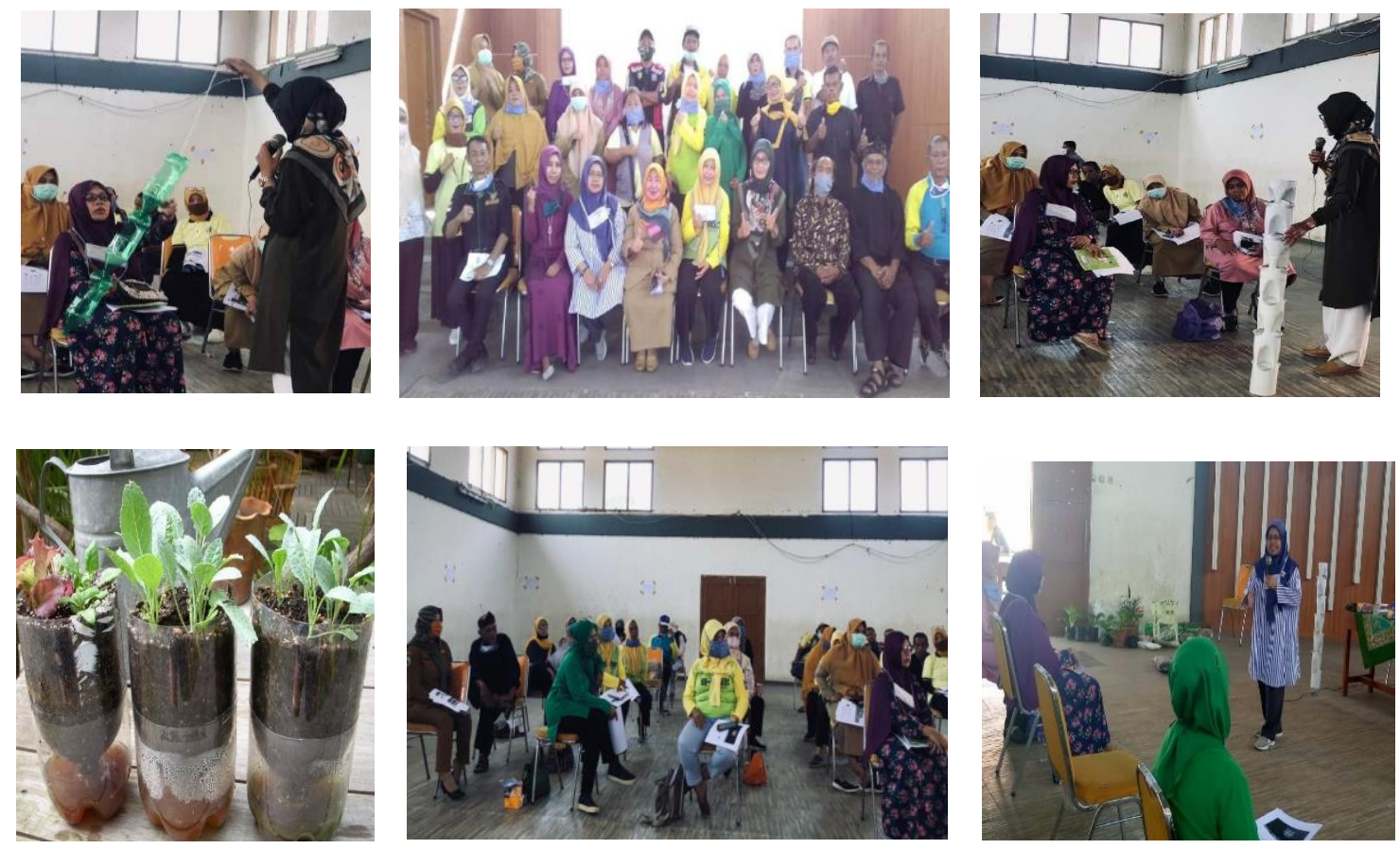

Gambar 2. Pelatihan budidaya sayuran secara vertikulture di Kelurahan Rancaekek Kencana

Setelah wadah dan media tanam disiapkan, langkah berikutnya adalah demontrasi praktek budidaya sayuran meliputi aktifitas : pemindahan bibit tanaman ke dalam pot, penyiraman setiap hari secara teratur pemberian pupuk dan pengendalian hama penyakit tanaman secara hayati dan pemanenan. Bibit tanaman yang digunakan dalam pelatihan ini adalah sayuran daun dengan masa tanam relatif singkat berkisar 25-35 hari yaitu tanaman kangkung, bayam dan pokcoy.

\section{Analisis biaya dan penerimaan Usahatani sayuan secara Vertikulture}

Penerapan teknik vertikultur ini dapat meningkatkan jumlah tanaman yang ditanam pada suatu areal tertentu hingga 3-10 kali lipat (Andoko,2004), sehingga produksi tanaman yang dihasilkan dapat meningkat. Untuk memudahkan evaluasi kelayakan ekonomi usahatani perlu 
dilakukan penilaian biaya dan penerimaan usahatani. Banyaknya produksi yang dihasilkan dalam usahatani mempengaruhi penerimaan petani. Pendapatan dihasilkan dari selisih antara penerimaan dan total biaya yang dikeluarkan petani. Besarnya total biaya dan penerimaan akan mempengaruhi besarnya pendapatan petani. Pada pelatihan ini peserta dibimbing untuk mencatat dan menghitung semua pengeluaran dan penerimaan usahatani sayuran secara vertikulture berdasarkan hasil perkiraan seperti tersaji pada Tabel 1.

Tabel 1. Analisi Biaya dan Penerimaan Usahatani sayuran Secara vertikultur di KWT Kencana Lestari di atas lahan 60 meter persegi

\begin{tabular}{|c|c|c|}
\hline No & Komponen Biaya & Jumlah (Rp) \\
\hline 1. & $\begin{array}{l}\text { Biaya Investasi Untuk } 3 \text { tahun : } \\
\text { - pot Vertikal berbahan bambu } \\
\text { bambu betung } 6 \text { unit @ } 15.000 \text {, Tali ijut } 10 \text { gulung @ } \\
5.000 \text { dan, upah pembuatan } 2 \text { HOK @ } 100.000 \\
\text { - Pot vertikal berbahan baku pipa PVC } 4 \text { inchi } 6 \text { unit @ } \\
75.000 \text { dop } 4 \text { inch } 12 \text { buah, upah pembuatan } 2 \text { HOK @ } \\
100.000 \\
\text { - } \quad \text { Tanah lembang } 10 \text { karung @ } 10.000 \\
\text { - } \quad \text { Arang sekam } 5 \text { karung @ } 25.000 \\
\text { - } \text { Kompos } 10 \text { karung @ } 5000 \\
\text { - } \quad \text { Polibag } 1 \text { kg @ } 45.000\end{array}$ & 698.000 \\
\hline 2 & $\begin{array}{l}\text { total biaya investasi } \\
\text { biaya variabel : } \\
\text { - } 12 \text { sachet Bibit kangkung @ 25.000, } 12 \text { sachet bibit } \\
\text { bayam @ } 30.000 \text { dan } 12 \text { sachet bibit pakcoy @ } 35,000\end{array}$ & 1.358 .000 \\
\hline & total biaya variabel & 6.080 .000 \\
\hline 3 & Total biaya per tahun & $6.532,667$ \\
\hline 4 & $\begin{array}{l}\text { Penerimaan : } \\
\text { - pakcoy 150 Kg@ } 15.000 \\
\text { - kangkung 225 Kg @ } 10.000 \\
\text { - bayam 175 Kg@ } 25.000\end{array}$ & 8.875 .000 \\
\hline 5 & Keuntungan & $2.342,333$ \\
\hline 6 & $\mathrm{R} / \mathrm{C}$ & 1,36 \\
\hline
\end{tabular}

Usia ekonomis rak dan polibag tanaman rata-rata diperkirakan adalah 3 tahun (36 bulan), maka biaya investasi per tahun adalah $\mathrm{Rp} 452.667,-$. Biaya variabel per tahun Rp 6.080 .000 , maka total biaya usahatani sayuran adalah Rp 6.532,667. Rasio penerimaan terhadap biaya adalah 1,36, artinya secara ekonomi usahatni sayuran tersebut layak untuk dilaksanakan karena dari setiap 100 rupiah investasi yang di keluarkan akan memberikan penerimaan sebesar 136 rupiah atau memberikan keuntungan sebesar 36 rupiah.

\section{Monitoring dan Evaluasi Budidaya Usahatani Sayuran di Kebun KWT Kencana Lestari}

Pada akhir kegiatan dilakukan evaluasi terhadap peserta dan proses pelaksanaan kegiatan. Berdasarkan kuesioner hasil evaluasi diketahui bahwa materi yang disampaikan 
dapat dimengerti dengan baik oleh peserta. Hasil post test menunjukkan terjadi peningkatan pengetahuan peserta pelatihan dari kondisi awal 63 persen jawaban pserta yang benar menjadi 95 persen artinya terjadi kenaikan pengetahuan sebesar 32 persen. Pada aspek sikap terjadi peningkatan keyakinan bahwa budidaya sayuran secara veretikulture dapat dilakukan dan akan memberikan keuntungan usaha. Peserta yang menyatakan tertarik untuk memulai kegiatan usaha budidaya sayuran secar veretikultur di lahan pekarangan berkisar 60 persen dari seluruh peseerta. Setelah ditelusuri terdapat berbagai faktor yang dipertimbangkan dalam menerapkan teknis budidayaini diantaranya terbatasnya waktu luang yang dimiliki peserta, sebagian peserta tidak memiliki lahan pekarangan dan faktor teknis lainnya. Pada saat dilakukan tanya jawab banyak peserta yang antusias bertanya dan beberapa orang pengurus KWT berkeinginan agar dilakukan pelatihan secara periodik terkait kegiatan usahatani sayuran secara khusus maupun kewirausahaan. Hasil evaluasi kegiatan menunjukkan terdapat beberap faktor yang mendukung keberhasilan kegiatan PKM yaitu : (a) Antusiasme yang sangat baik dari pengurus KWT kencana Lesatari dan aparat Kelurahan dalam bentuk fasiliasi kegiatan, (b) kekompakan anggota KWT dalam mengikuti acara dari awal hingga selesai, serta tersedianya kebun KWT sebagai tempat edufarming untuk anggota KWT dan masyarakat umum. Sedangkan faktor penghambat utama dari kegiaan ini adalah waktu pelaksanaan pelatihan pada saat pandemik covid 19 berlangsung sehingga terdapat keterbatasan dalam pelaksanaan ceramah dan juga praktek budidaya karena harus menerapkan SOP Covid 19 berupa menjaga jarak dan penggunaan masker.

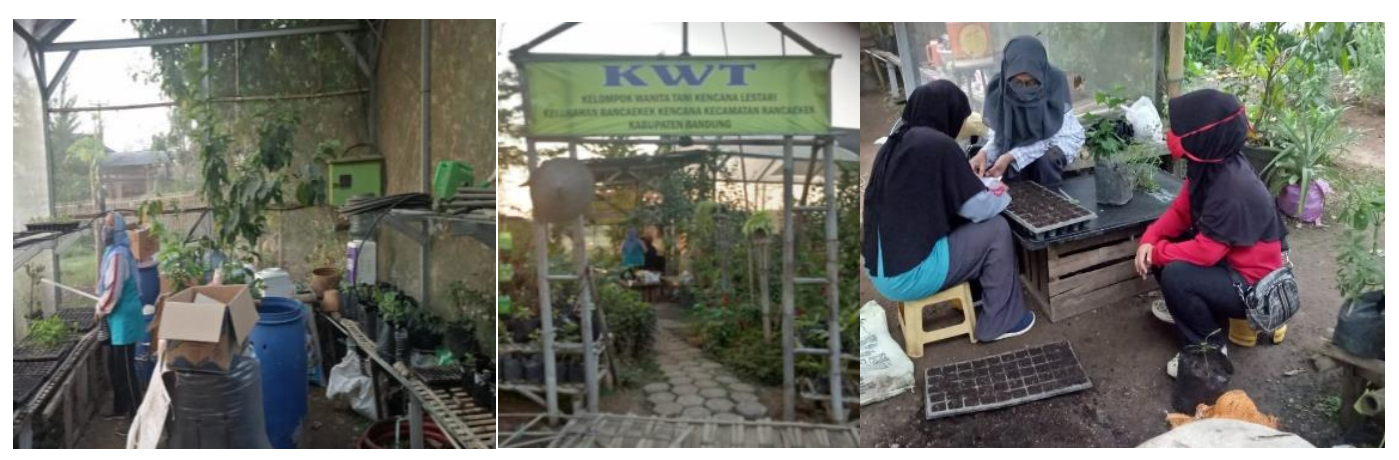

Gambar 3. Kunjungan dan evaluasi di Kebun KWT Kencana Lestari

\section{KESIMPULAN}

Kegiatan ini telah memberikan manfaat bagi peserta. Manfaat yang dirasakan adalah terjadi perubahan yang cukup signifikan dari sisi kognitif, yaitu bertambahnya tingkat pengetahuan ibu-ibu anggota KWT Kencana Lestari mengenai teknis budidaya tanaman sayuran secara Vertikultur. Peningkatan aspek psikomotorik peseta pelatihan bertambah keyakinannya bahwa budidaya sayurans ecara vertikultur dapat dilaksanakan dengan mudah karena keterampilan mereka sudah bergambah . Kegiatan PKM ini menjadi salah satu solusi praktis dalam mengatasi masalah budidaya di lahan terbatas. Secara ekonomi, kegiatan ini dapat mengurangi pengeluaran rumah tangga dalam mengkonsumsi sayuran dan memberikan sumber pendapatan bagi keluarga. Hasil analisis biaya dan penerimaan usahatani sayuran secara vertikultr di kebun KWT Kencana Lestari pada lahan 60 meter pesegi menunjukkan rata-rata pendapatan atas biaya total sebesar Rp. 2.342,333 per tahun dengan R/C sebesar 1,36. Artinya kegitan usahani ini layak untuk diteruskan. Guna meningkatkan produktifitas dan perluasan pasar produk sayuran dari KWT ini , maka upaya pendampingan masih diperlukan 


\section{DAFTAR PUSTAKA}

Ahmad Sarwadi (2018), Pemanfaatan Area Pekarangan Sebagai Lanskap Produktif di Permukiman Perkotaan. Tesa Arsitektur Vol.16 |No.1 || hal. 40 - 48.

Andoko, Agus. 2004. Budi Daya Cabai Merah Secara Vertikultur Organik. Penebar Swadaya. Jakarta.

BPS, 2019. Kecamatan Rancaekek dalam Angka 2018.

Lilis Laeni, 2020. Selayang pandang KWT Kencana Lestari di Kampung Saber Kencana

Nurul H, dkk . 2018. Pemanfaatan lahan sempit untuk budidaya sayuran dengan sistem vertikultur (Utilization of narrow-land area to cultivate vegetables by verticulture syste). Online: http://jurnal.umpalangkaraya.ac.id/ejurnal/pgbmu

Prabowo, R. 2010. Kebijakan pemerintah dalam mewujudkan ketahanan pangan di Indonesia Mediagro, 6(2), 62-73.

Rauf, Rahmawaty, \& Budiati, D. 2013. Sistem pertanian terpadu di lahan pekarangan mendukung ketahanan pangan berkelanjutan dan berwawasan lingkungan. Jurnal Online Pertanian Tropik Pasca Sarjana FP USU, 1(1), 1-8. 